Toshikatsu Shinka Takushi Naroda Takamichi Tamura

Kenji Sasahara • Yutaka Nakahori

\title{
A rapid and simple method for sex identification by heteroduplex analysis, using denaturing high-performance liquid chromatography (DHPLC)
}

Received: October 31, 2000 / Accepted: February 5, 2001

\begin{abstract}
A novel method for sex identification, using a denaturing high-performance liquid chromatography (DHPLC) system, is described. Among many methods for identifying sex, the most popular and credible system has been the polymerase chain reaction (PCR) method, using nucleotide primer sets of the amelogenin gene, which is shared on both the $\mathrm{X}$ and $\mathrm{Y}$ chromosomes. With this conventional method, the judgment depends on detection of the size difference between the PCR products derived from the $\mathrm{X}$ and $\mathrm{Y}$ chromosomes. In this study, we adopted DHPLC to detect the difference by checking heteroduplex formation between the products, which enabled us to shorten the PCR products to $45 \mathrm{bp}$ and the separation time to within a period of $8 \mathrm{~min}$ per sample. This new system may have wide applications in many different fields, such as forensic medicine, prenatal diagnosis, inbreeding of animals, and anthropology.
\end{abstract}

Key words Sex identification $\cdot$ Amelogenin $\cdot$ DHPLC $\cdot X$ chromosome $\cdot$ Y chromosome

\section{Introduction}

For many fields, such as forensic medicine and prenatal diagnosis, a rapid and accurate sex identification system is very important. A polymerase chain reaction (PCR)based sex identification system, using primer sets of the amelogenin gene, is conventionally used because of its sim-

T. Shinka $\cdot$ T. Tamura $\cdot$ K. Sasahara $\cdot$ Y. Nakahori $(\bowtie)$ Department of Public Health, School of Medicine, University of Tokushima, Kuramoto-cho, Tokushima 770-0085, Japan Tel. +81-886-33-7075 ext. 2272; Fax +81-886-33-7453

e-mail: nakahori@basic.med.tokushima-u.ac.jp

T. Naroda

Department of Urology, School of Medicine, University of

Tokushima, Tokushima, Japan plicity (Nakahori et al. 1991b; Sullivan et al. 1993; Mannuci et al. 1994)

The PCR-based sex identification using primer sets of the amelogenin gene has some advantages, as follows (Nakahori et al. 1991b): first, with the PCR-based method, only a small amount of genomic DNA is necessary for the analysis. Second, the PCR product derived from the X chromosome is, automatically, a positive control, because both males and females have at least one $\mathrm{X}$ chromosome (Nakahori et al. 1991a). This conventional system depends on the difference in the length of the PCR products derived from the X and Y chromosomes. Therefore, separation of the PCR products, using electrophoresis, must be done.

In recent years, a denaturing high-performance liquid chromatography (DHPLC) system has been developed (Underhill et al. 1996, 1997). This system, which combines an HPLC system and heteroduplex analysis, has very high sensitivity for detecting mutational changes in nucleotides (Wagner et al. 1999a, b).

Here, we show a useful method for sex identification, using a DHPLC system, based on heteroduplex analysis with primer sets of the amelogenin gene; we also discuss the wider application of the system.

\section{Materials and methods}

DNA extraction. Genomic DNAs were prepared from peripheral leukocytes according to the standard method (Maniatis et al. 1983).

PCR conditions. The reaction was performed in a total volume of $20 \mu \mathrm{l}$, containing $5 \mathrm{ng}$ genomic DNA, $1.5 \mathrm{mM}$ $\mathrm{MgC}_{12}, 10 \mathrm{mM}$ of a TrisHCl-buffer $(\mathrm{pH} 8.3), 50 \mathrm{mM} \mathrm{KCl}$, $0.001 \%(\mathrm{w} / \mathrm{v})$ gelatin, $0.25 \mathrm{mM}$ of each dNTP, $1 \mu \mathrm{M}$ of each primer, and $0.1 \mathrm{U}$ of Ampli Taq Gold DNA polymerase (Perkin-Elmer, Norwalk, CT, USA). The above were cycled at $94^{\circ} \mathrm{C}$ for $9 \mathrm{~min}$, followed by 35 cycles of $94^{\circ} \mathrm{C}$ for $30 \mathrm{~s}, 60^{\circ} \mathrm{C}$ for $30 \mathrm{~s}$, and $72^{\circ} \mathrm{C}$ for $1 \mathrm{~min}$, and a final extension at $72^{\circ} \mathrm{C}$ for $10 \mathrm{~min}$. Finally, for heteroduplex formation, 
each PCR product was denatured at $95^{\circ} \mathrm{C}$ for $5 \mathrm{~min}$ and gradually cooled to $10^{\circ} \mathrm{C}$.

DHPLC analysis. DHPLC analysis has already been described elsewhere (Underhill PA et al. 1996; 1997). In brief, after heteroduplex formation of the PCR products, $2 \mu \mathrm{l}$ of each PCR product was automatically submitted to 264injection and analyzed using the WAVE system (Transgenomic, Omaha, NE, USA). The flow speed and the ratio of the buffer system were determined using the WAVE system software.

\section{Results}

A PCR system using primer sets of the amelogenin gene simultaneously amplified the fragments derived from both the $\mathrm{X}$ and $\mathrm{Y}$ chromosomes. All primer sets, listed in Table 1 , worked well. The sequences of PCR products derived from the $\mathrm{X}$ and $\mathrm{Y}$ chromosomes were similar, except for some deletions and base substitutions (Table 1). Therefore, heteroduplex formation between the PCR products derived from the $\mathrm{X}$ and $\mathrm{Y}$ chromosomes occurred readily. After heteroduplex formation, sex identification was carried out, using the DHPLC system. The temperature of the oven for the DHPLC system was increased to $62^{\circ} \mathrm{C}$ for the primer sets AME I and II, and to $60^{\circ} \mathrm{C}$ for AME III. Male-specific and female-specific peak profiles were easily detectable with each primer set. Each primer set gave good reproducible chromatograms (Fig. 1). The primer set AME I generated one peak for females and two for males. The primer set AME II generated two peaks for females and three for males. For the AME III primer set, which can amplify only a 45-bp fragment of the amelogenin gene, several peaks were observed for both females and males. In addition to these common peaks, a Y-specific peak was also detected for males. For each primer set, we carried out sex identification in a total of 20 samples whose sex had already been determined using the conventional PCR-based method with the primer set of the amelogenin gene. The sexes determined in each sample using our method were completely consistent with those determined using the conventional method.

\section{Discussion}

We developed a simple method for sex identification, using a DHPLC system. We combined the DHPLC system and a sex identification system, using primer sets of the amelogenin gene. The conventional PCR-based sex identification using this primer set has some advantages. Even a small amount of sample DNA is enough for sex identification. The primer sets of the amelogenin gene can simultaneously amplify the fragments derived from both the $\mathrm{X}$ and $\mathrm{Y}$ chromosomes. Because the $\mathrm{X}$ chromosome is shared by males and females, the PCR product derived from the $\mathrm{X}$ chromosome automatically becomes a positive control for the reaction.

In addition to these advantages, our sex identification system has further advantages. The conventional sex identification system depends on the difference in the length of the PCR products derived from the different sex chromosomes, determined using gel electrophoresis (Nakahori et al. 1991b). Therefore, the length of the PCR products is a critical matter. Our system, on the other hand, depends on the heteroduplex formed between the fragments derived from the two sex chromosomes. The DHPLC system can detect both differences in the length and in the nucleotide base substitutions, of the PCR products (Underhill et al. 1996; 1997). Therefore, for our system, the length of the PCR products is not so critical, and they can be shorter than those used in the conventional method. In this study, we identified the sex using only 45-bp fragments of the amelogenin gene. Therefore, our sex identification system has an advantage in regard to the analysis of crude or fragmented DNA samples. Furthermore, because our system is based on DHPLC, analysis for sex identification can be carried out automatically without any gels, within a time period of $8 \mathrm{~min}$ per sample.

In this study, the primer sets AME II and AME III generated more than two peaks on the chromatograms for both males and females. Several possible explanations can be given for this finding. Under the conditions used in this study, several stable heteroduplexes were formed. If the PCR products are short, such products may easily form heteroduplexes with primers, and such heteroduplexes may generate complex peak patterns.

Table 1. List of primer sets of the amelogenin gene used in this study, and characteristics of the PCR products

\begin{tabular}{llllc}
\hline Primer set & Primer & Sequence & $\begin{array}{l}\text { Length of PCR } \\
\text { products (bp) }\end{array}$ & $\begin{array}{l}\text { Differences between X } \\
\text { and Y fragments }\end{array}$ \\
\hline AME I & Forward: Amel A & 5'-CCCTGGGCTCTGTAAAGAATAGTG & X:106 & 7 Base substitutions and \\
& Reverse: Amel B & 5'-ATCAGAGCTTAAACTGGGAAGCTG & Y:112 & base deletions \\
AME II & Forward: Amel NS1 & 5'-CCCCTTTGAAGTGGTACCAG & X:81 & 4 Base substitutions and \\
& Reverse: Amel NS2 & 5'-GCATGCCTAATATTTTCAGGG & Y:84 & 3 base deletions \\
AME III & Forward: Amel NF & 5'-CTTGCCTCCTAGCATATAAG & X:45 & 1 Base substitution \\
& Reverse: Amel NR & 5'-CCATCACACACATTCTTCATC & Y:45 & \\
\hline
\end{tabular}

PCR, Polymerase chain reaction

${ }^{a}$ Primers Amel A and Amel B have already been reported elsewhere (Beraud-Colomb et al. 1995) 
Fig. 1A-C. Examples of sex identification using denaturing high-performance liquid chromatography (DHPLC) system. Each primer set generated different peak profiles. The peak profiles for females and males are overlaid on each chromatogram. A Primer set AME I; B primer set AME II; C primer set AME III. Although the retention time for heteroduplex and homoduplex formation is not completely reproducible, the shape of the wave complexes is usually reproducible. The arrow in $\mathbf{C}$ shows a male-specific peak. The vertical and horizontal scales show the intensity of the peak, and the time elapsed after injection, respectively
A

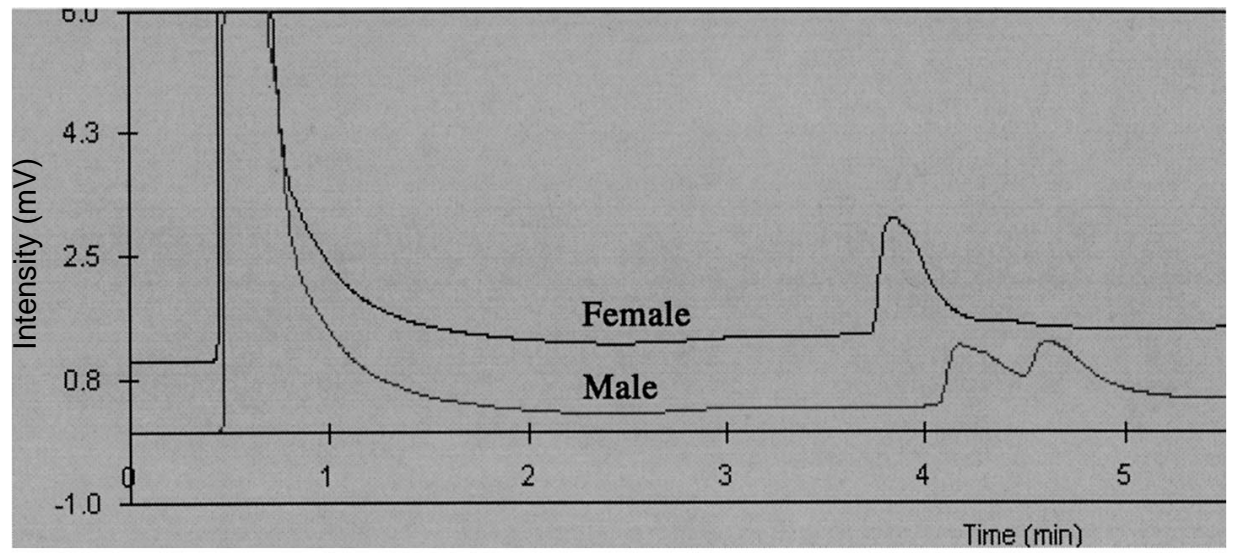

B

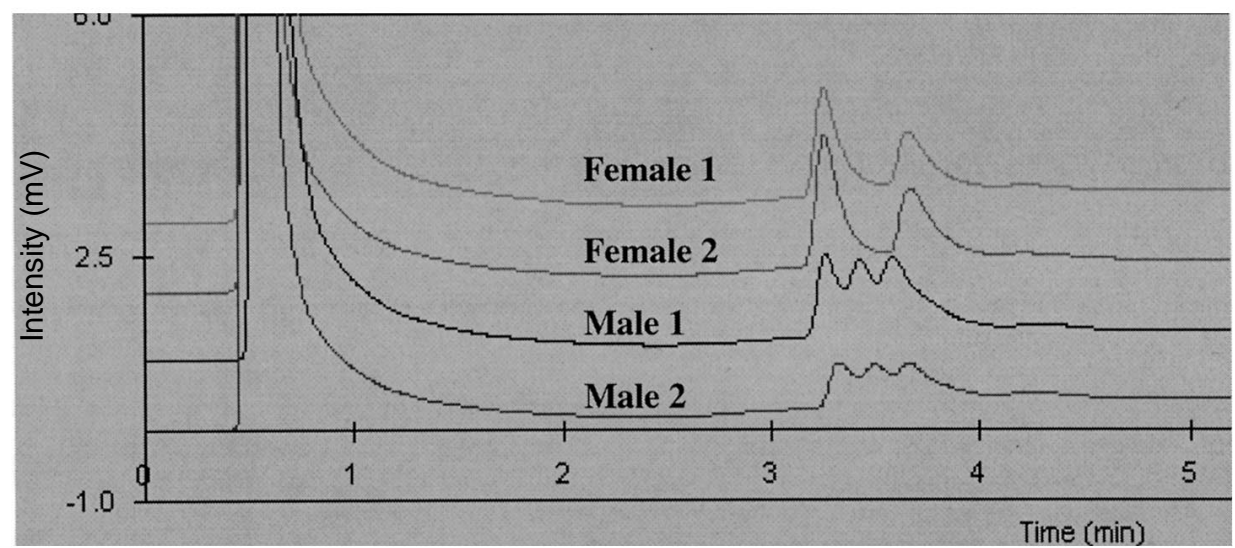

C

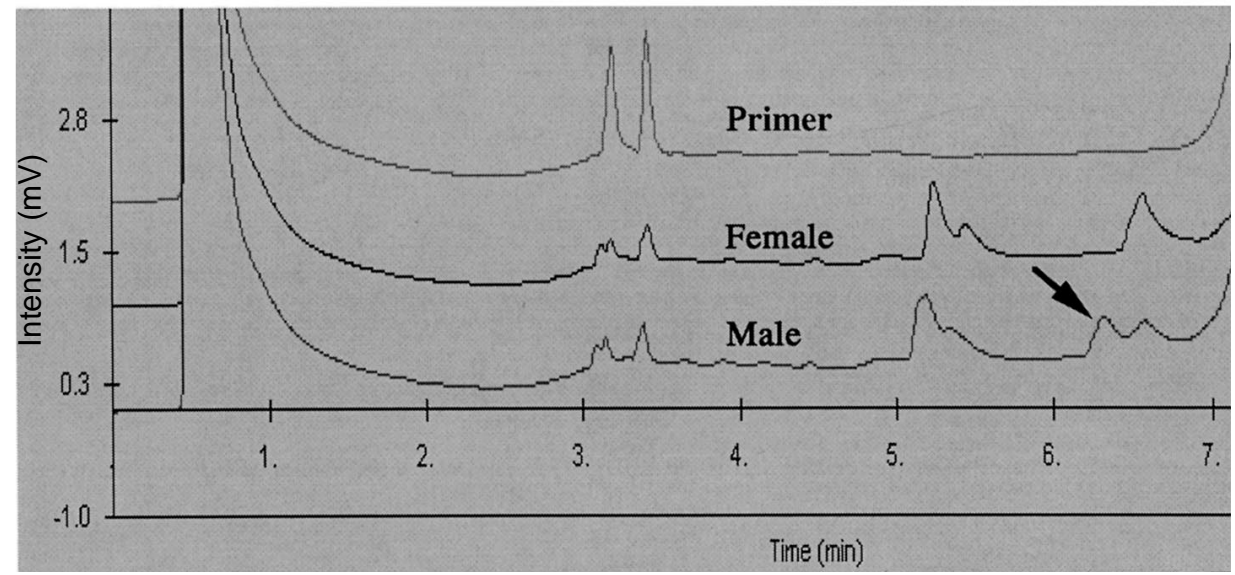

Because our method, essentially, depends on detecting heteroduplexes formed between different sex chromosomes, our heteroduplex-based sex identification system will become easier to use if new equipment for detecting heteroduplexes is developed.

In conclusion, we have described a novel sex identification system, based on heteroduplex analysis, using a DHPLC system. Our new sex identification system is very simple to use, and is widely applicable. We are convinced that our new method will have wide applications in many different fields.

Acknowledgments We thank Miss Yukiko Unemi and Miss Keiko Tsuji for technical assistance. This study was supported by the Core Research for Evolutional Science and Technology (CREST). 


\section{References}

Beraud-Colomb E, Roubin R, Martin J, Maroc N, Gardeisen A, Trabuchet G, Goossens M (1995) Human beta-globin gene polymorphisms characterized in DNA extracted from ancient bones 12000 years old. Am J Hum Genet 57:1267-1274

Maniatis T, Fritsch E, Sambrook J (1983) Molecular cloning: a laboratory manual. Cold Spring Harbor, New York

Mannuci A, Sullivan KM, Ivanov PL, Gill P (1994) Forensic application of a rapid and quantitative DNA sex test by amplification of the X-Y homologous gene amelogenin. Int J Legal Med 106:190193

Nakahori Y, Takeneka1 O, Nakagome Y (1991a) A human X-Y homologous region encodes "amelogenin". Genomics 9:264-269

Nakahori Y, Hamano K, Iwaya M, Nakagome Y (1991b) Sex identification by polymerase chain reaction using $\mathrm{X}-\mathrm{Y}$ homologous primer. Am J Med Genet 39:472-473
Sullivan K, Mannuci A, Kimpton CP, Gill P (1993) A rapid and quantitative DNA sex test: fluorescence-based PCR analysis of $X-Y$ homologous gene amelogenin. Biotechniques 15:636-638

Underhill PA, Jin L, Zemans R, Oefner PA, Cavalli-Sorza LL (1996) A pre-Columbian human $\mathrm{Y}$ chromosome-specific $\mathrm{C}$ to $\mathrm{T}$ transition and its implications for human evolution. Proc Natl Acad Sci USA 93:196-200

Underhill PA, Jin L, Lin AL, Mehdi SQ, Jenkins T, Vollrath D, Davis R, Cavalli-Sorza LL, Oefner PA (1997) Detection of numerous Y chromosome biallelic polymorphisms by denaturing high performance liquid chromatography. Genome Res 7:996-1005

Wagner TMU, Hirtenlehner K, Shen P (1999a) Global sequence diversity of BRCA2: analysis of 71 breast cancer famillies and 95 control individuals of worldwide populations. Hum Mol Genet 8: 413-423

Wagner T, Stoppa-Lyonnet D, Fleischmann E, Muhr D, Pagese S, Sandberg T, Caux V, Meslinger R, Langbauer G, Borg A, Oefner PA (1999b) Denaturing high performance liquid chromatography (DHPLC) detects reliably BRCA1 and BRCA2 mutations. Genomics 62:369-376 